\title{
¿Quién juzga a los que juzgan? El enjuiciamiento de magistrados en la provincia de Buenos Aires (Argentina, 1821-1878)*
}

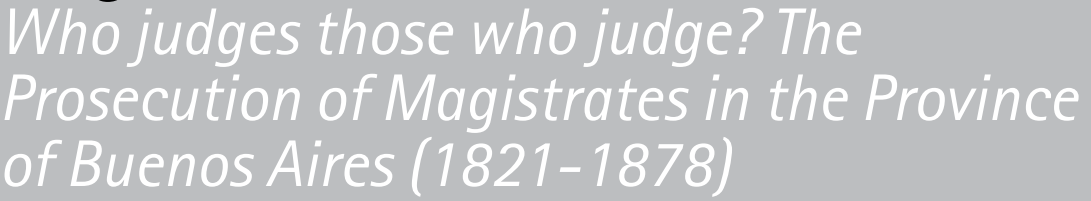

María Angélica Corva**

\begin{abstract}
RESUMEN
El objetivo de nuestro trabajo es determinar y analizar los cambios generados en los responsables y en el procedimiento del enjuiciamiento de los jueces acusados de delito en el ejercicio de sus funciones, focalizando la atención en la trayectoria de los enunciados normativos de garantías, para el magistrado como administrador de justicia y para la sociedad como receptora de esa justicia, a través de los reglamentos y textos constitucionales, con los debates correspondientes. En el contexto de las doctrinas políticas expuestas y de la institución finalmente conformada, intentaremos ahondar en la experiencia politica de la sociedad previa a la carta constitucional, a través de una causa iniciada contra un juez que, acusado por medio de la prensa de apropiarse de fondos sucesorios, fue procesado por sus pares. Determinaremos luego los pasos dados hasta la definición del jurado de enjuiciamiento analizando los debates constituyentes y legislativos.
\end{abstract}

PALABRAS CLAVE: Enjuiciamiento de magistrados, Gobierno judicial, Poder Judicial, opinión pública, provincia de Buenos Aires.

\begin{abstract}
The objective of our work is to determine the changes in those responsible and in the procedure of the indictment of judges accused of a crime in the exercise of their duties. The attention is focused on the trajectory of the Normative Statements of Guarantees, for the magistrate as administrator of justice and for society as recipient of that Justice, through the Regulations and Constitutional texts, with the corresponding debates. In the context of the exposed Political Doctrines and the institution finally accredited, we will try to delve into the political experience of the society prior to the Constitutional Charter, through a case initiated against a judge who, accused by the press of appropriating inheritance funds, was processed by his peers. We will then determine the steps to the definition of the Trial Jury by analyzing the Constituent and Legislative Debates.
\end{abstract}

\section{KEY WORDS:}

Prosecution of Magistrates, Judicial Government, Judiciary, Public Opinion, Province of Buenos Aires.

\footnotetext{
* Artículo de investigación. Recibido el 28 de septiembre de 2017 y aceptado para su publicación el 16 de agosto de 2018.

** Investigadora del Instituto de Investigaciones de Historia del Derecho (INHIDE) Argentina. (mariacorva@gmail.com) orcid.org/0000-0002-1970-2518
} 


\section{SUMARIO}

1. Introducción

2. La atribución de superintendencia

3. El caso Agrelo: prensa, opinión pública y administración de justicia

4. El enjuiciamiento de magistrados en la Constitución de 1873 y su legislación

5. Conclusiones

\section{Introducción}

En el siglo XIX, en Latinoamérica, hubo una temprana adopción de formas republicanas y representativas de gobierno, basadas en la soberanía del pueblo. Por ello, para abordar la construcción del poder, una cuestión primordial es estudiar el diseño de las instituciones de gobierno, que generó alternativas y proyectos diversos, con formas muy distintas de ejercicio de la autoridad y conflictos sobre la definición y el control del poder. ${ }^{1}$

Las decisiones respecto a la división funcional de poderes, en relación con los dispositivos institucionales y el funcionamiento de cada uno de ellos, dieron lugar a debates, ensayos y tensiones, centrados fundamentalmente en las diferentes maneras de concebir la constitución de los poderes. En el proyecto liberal, el poder judicial tenía asignada la función de garantizar la legitimidad del sistema político republicano. Sin embargo, había diversas miradas sobre el cómo, además, no fue completamente independiente, debido al presupuesto, los nombramientos y el jury de enjuiciamiento.

Cada una de estas cuestiones sigue generando discusiones y conflictos que involucran a la administración de justicia, en particular, y a la sociedad, en general. Trataremos aquí el enjuiciamiento de los magistrados judiciales. Este tema no se limita al análisis de la destitución o remoción del cargo, sino que tiene una estrecha relación con la disciplina en la magistratura y con la responsabilidad por los errores y actos perjudiciales de la actividad jurisdiccional. La cuestión disciplinaria y correctiva de la magistratura no ha sido suficientemente analizada. Se suele fijar la atención únicamente en el juicio político o el jurado de enjuiciamiento, imposición máxima que revoca el acto administrativo del nombramiento. ${ }^{2}$

\footnotetext{
'SÁBATO, HILDA, Buenos Aires en armas. La revolución de 1880, Buenos Aires, Siglo XXI, 2008, pp. 9-10.

2 Paolin, Jorge Omar, El enjuiciamiento de magistrados y funcionarios, Buenos Aires, La Ley, 1992, pp. 49-50.
} 
En los últimos años, se ha puesto en la mira a los sistemas judiciales de América Latina, reactivando el interés académico de los países de la región por el estudio de la administración de justicia. ${ }^{3}$ La sociedad y los magistrados y funcionarios judiciales reclaman continuamente una justicia más accesible, rápida y eficiente, que logre reconciliar la administración de justicia con la ciudadanía latinoamericana. Esto requiere definir el papel que se le asigna a un poder del Estado, el cual debe tener un rol decisivo en el orden democrático, el sistema de garantías y los derechos humanos.

La historia debe contribuir a esclarecer el rol, funcionamiento, alcances y limitaciones de la justicia como defensora de los derechos del ciudadano. Así, ha de ayudar a conocer y comprender cómo, en el proceso de institucionalización del Estado, el Poder Judicial tiene ciertas características. ${ }^{4}$

De este modo, es ineludible contribuir en este proceso a través del estudio histórico jurídico del enjuiciamiento de magistrados de la provincia de Buenos Aires. La tarea es compleja dado que, desde su génesis, la atribución de superintendencia del máximo tribunal abarcaba la medida extrema de suspender y destituir al magistrado por su mala conducta. El texto constitucional provincial de 1873, que definió la estructura y funcionamiento del Poder Judicial, dividió claramente la superintendencia del enjuiciamiento. En el artículo 190, estableció que los jueces de las Cámaras de Apelación y de primera instancia podían ser acusados por cualquiera del pueblo, por delitos o faltas cometidas en el desempeño de sus funciones ante un jury calificado, compuesto de siete diputados y cinco senadores profesores de derecho.

Este jury terminó de definirse en 1878 , al sancionarse la ley que lo reglamentó en función de lo dispuesto. La Suprema Corte de Justicia de la Provincia de Buenos Aires quedaba entonces a cargo de la superintendencia del poder judicial. Entre sus atribuciones, incluía la de tomar medidas disciplinarias sobre magistrados y funcionarios. Sin embargo, hasta que llegó la sanción de la ley de jury, esa función de gobierno judicial implicaba no sólo apercibir a los jueces por el incumplimiento de su deber, sino también suspender, investigar y mandar a enjuiciar criminalmente a los que fueran acusados de un delito mientras desempeñaban su función.

Esta atribución, tomada en gran parte del Tribunal Supremo Español, no se entendía como "depresiva de la dignidad del magistrado, que fuerte en la convic-

\footnotetext{
3 Palacio, Juan Manuel y Candioti, Magdalena, Justicia, política y derechos en América Latina, Buenos Aires, Prometeo Libros, 2007.

${ }^{4}$ Corva, Maria Angéulca, "La Administración de Justicia, una mirada desde la Historia del Derecho", Portal Jurídico Interdisciplinario Pólemos. Disponible: http://polemos.pe/la-administracion-justicia-una-mirada-desde-la-historiadel-derecho/
} 
ción de su derecho y en la legalidad de sus procederes, debe ver en ella el medio legítimo de levantar hasta la más leve sombra de acusaciones injustificadas". ${ }^{5}$ Aún después de sancionada la Constitución, el máximo tribunal se reservaba dicha potestad hasta que se reglamentara el jury, dejando de manifiesto el carácter transicional y complejo de la construcción del Estado provincial hacia el orden liberal que se intentaba instaurar.

El objetivo de nuestro trabajo es determinar y analizar los cambios generados en los responsables y en el procedimiento del enjuiciamiento de los jueces acusados de delito en el ejercicio de sus funciones. La atención estará puesta en la trayectoria de los enunciados normativos de garantías, para el magistrado -como administrador de justicia- y para la sociedad -como receptora de esa justicia-, a través de los reglamentos y textos constitucionales, con los debates correspondientes.

En el contexto de las doctrinas políticas que serán expuestas y de la institución finalmente conformada, intentaremos ahondar en la experiencia política de la sociedad previa a la carta constitucional. Esto, a través de una causa iniciada contra un juez quien, por medio de la prensa, fue acusado de apropiarse de fondos sucesorios. De tal modo, éste fue procesado por sus pares.

Cuando usamos el concepto sociedad, tenemos presente que estamos estudiando un periodo en el cual la participación política estaba restringida a una élite conformada por abogados, intelectuales, periodistas, entre otros. Sin embargo, esta sociedad política convivía y era sostenida por una sociedad civil, que encontraba cauces informales de participación y reclamo. Además, esa élite no era homogénea, no todos pensaban igual. Por ello, en muchas ocasiones, existieron posturas opuestas en temas decisivos para la nueva organización liberal como la administración de justicia, puesta de manifiesto en los debates.

Partiendo de estas premisas, en primer lugar, definiremos la atribución de superintendencia, presente desde la Real Audiencia, que contaba con un gran poder de vigilancia y control sobre la administración de justicia. Esta atribución se ejercía sobre los organismos encargados de dirimir las controversias jurídicas de los particulares y sobre todo lo relacionado con el recto ordenamiento de

\footnotetext{
${ }^{5}$ Acuerdos y sentencias dictadas por la Suprema Corte de Justicia de la Provincia de Buenos Aires, Autos acordados desde 1810, acuerdos extraordinarios, resoluciones y noticias referentes a la administración de justicia. Segunda edición autorizada, realizada por el secretario de la Suprema Corte, Dr. Aurelio Prado y Rojas, Buenos Aires, Jacobo Peuser, 1892 (en adelante Acuerdos y Sentencias), tomo I, pp. 669-670. Causa CCXXVIII. "La Suprema Corte tiene jurisdicción sobre los delitos y faltas de los magistrados, en el ejercicio de sus cargos, mientras no se dicten las leyes orgánicas y reglamentarias del art. 190 de la Constitución, y aún después de dictadas, en aquellos casos que no estén comprendidos en ellos". Podia llamar a su seno a cualquier magistrado judicial para prevenirlo por faltas u omisiones.
} 
la administración, en pos de mantener el ideal de justicia al cual aspiraba el régimen indiano. ${ }^{6}$

Luego, nos dedicaremos al caso de Emilio Agrelo quien, acusado de realizar sustracciones de depósitos judiciales sucesorios, fue suspendido, investigado y mandado a enjuiciar por el Superior Tribunal de Justicia. Este proceso nos permitirá seguir la conexión que, en esos años de profundos cambios, se estableció entre la opinión pública y la justicia, por medio de la prensa. Cabe aclarar que no se trata de un estudio de caso, sino del único caso en que el Superior Tribunal se vio obligado a hacer uso de esta atribución, lo cual nos permite conocer el procedimiento y las tensiones generadas. ${ }^{7}$

Finalmente, determinaremos los pasos que se dieron hasta la definición del jurado de enjuiciamiento, analizando los debates constituyentes y legislativos. La reglamentación y organización del juicio por jurado permitió poner en funcionamiento los diferentes mecanismos de control, propios de los diversos tipos de responsabilidad de los magistrados. La responsabilidad civil surge de los actos ilegítimos o irregulares con que los magistrados perjudican al Estado o a terceros. La responsabilidad penal se genera cuando un funcionario realiza un acto que constituye un delito previsto en el Código Penal o en leyes especiales. La responsabilidad administrativa contempla conductas que alteran el buen funcionamiento de la administración de justicia. La responsabilidad política se establece cuando un funcionario debe dar cuenta a otro sobre la función que le fue asignada. ${ }^{8}$

\section{La atribución de superintendencia}

La superintendencia asigna a la autoridad superior el ejercicio de ciertas facultades de dirección u ordenamiento; la posibilidad de sancionar es intrínseca a sus atribuciones. Ello implica un poder disciplinario, que permite adoptar todas las medidas necesarias para que los miembros del cuerpo judicial observen la conducta y responsabilidad en el desempeño de su función, con el objeto de asegurar el óptimo desenvolvimiento del servicio.

\footnotetext{
${ }^{6}$ Zorraquin Becú, Ricardo, La organización judicial argentina en el período hispano, Buenos Aires, Libreria del Plata, 1952, pp. 186-188.

7 Podemos afirmar que este caso es único porque lo descubrimos en una recopilación de los acuerdos y sentencias de la Suprema Corte, realizada por su primer secretario, Aurelio Prado y Rojas, publicado en 1878 y que reúne todos los antecedentes desde 1778. Después de una larga búsqueda dimos con el expediente, que tenía cuatro cuerpos de los que se conservan dos. El resto del caso lo reconstruimos con otras fuentes.

${ }^{8}$ Brianti, Susana Alicia, "El jurado de enjuiciamiento de magistrados y funcionarios de la Provincia de Buenos Aires y la Suprema Corte de Justicia. Facultades", Buenos Aires, La Ley, 2008.
} 
Como toda actividad que exige el concurso y colaboración de personas, sean jueces, funcionarios o empleados, la función jurisdiccional también requiere de una organización jerárquica y una subordinación disciplinaria de sus miembros. ${ }^{9}$ La Suprema Corte de Justicia provincial, creada por la Constitución de 1873 e instalada en 1875, definió la atribución de superintendencia como el "gobierno judicial", que requería contar con "los resortes de superintendencia, la facultad de las medidas disciplinarias y las inherentes a todo poder para la conservación de la disciplina y el buen régimen de la administración de justicia”. ${ }^{10}$

Para comprender esta potestad disciplinaria y sus alcances, es necesario remontarnos al concepto de gobierno de la justicia en Hispanoamérica. Para ello, es un buen punto de partida la definición que Carlos Garriga realiza de los difusos límites entre las inclinaciones de la persona privada frente a las obligaciones de la persona pública que conviven en todo juez. Esa tensión atravesaba el universo de la justicia y se resolvía en el tribunal de la conciencia. Pero esto significaba para el rey un instrumento y un obstáculo que obligaba a la Corona a desplegar una política judicial constantemente vigilante.

Entonces, la garantía última de la justicia estaba en la conciencia del rey "que la descarga y desempeña su oficio organizando el gobierno de la justicia, es decir construyendo un aparato apto para la administración de la justicia, y velando constantemente por su realización". ${ }^{11}$ Esta necesidad de garantir la administración de justicia no sólo se mantiene plenamente vigente, sino que se hace indispensable cuando el soberano es el pueblo y debe encontrar la vía para constituir el gobierno.

En el Río de la Plata la función de gobierno, diferente de la función jurisdiccional propia de la administración de justicia, tuvo sus antecedentes en la segunda Real Audiencia de Buenos Aires, instalada en 1784. Con la competencia de Tribunal Superior de Justicia, entendía en tercera instancia de las apelaciones que se interponían contra los fallos de los gobernadores, intendentes u otros jueces de su jurisdicción. Estaba compuesta por un presidente (el virrey), un regente, cuatro oidores, un fiscal y tenía la superintendencia de tribunales y cárceles, así como toda la materia llamada de subalternaría. Por tal, el presidente de la Audiencia debía nombrar un oidor cada año, para que fuera visitador de sus ministros y oficiales. ${ }^{12}$

\footnotetext{
${ }^{9}$ De la Colina, Salvador, Derecho y legislación procesal. Materia civil y comercial, tomo 1, Buenos Aires, Librería Nacional J. Lajouane \&t Cía. Editores, 1915; SANta CRuz, José MariA, El Poder disciplinario judicial. Responsabilidad administrativa de magistrados, funcionarios y empleados, La Plata, 1978.

${ }^{10}$ Acuerdos y sentencias, tomo 1, pp. 408-411, 641-643 y 669-670.

${ }^{11}$ GarRiga, Carlos, "Sobre el gobierno de la justicia en Indias (siglo XVI-XVII)", Revista de Historia del Derecho, núm. 34, p. 83.

${ }^{12}$ Leyes de Indias, libro $\|$, título xv, ley cixIx.
} 
A partir de 1810, año en que se inició el proceso de independencia de España, la Real Audiencia siguió en funciones, pero con nuevos jueces que fueron nombrados el 22 de junio. En su juramento, se les exigía desinterés, imparcialidad, justicia y la vida por la defensa de Fernando VII. ${ }^{13}$ El 23 de enero de 1812, los miembros del Primer Triunvirato y su secretario firmaron el reglamento de institución y administración de justicia. Éste aseguraba que no había felicidad pública sin una buena y sencilla administración de justicia, para lo cual se requería de "magistrados sabios que merezcan la confianza de sus conciudadanos".

El Reglamento de 1812 suprimió el tribunal de la Real Audiencia y lo sustituyó por una cámara de apelaciones para los negocios de grave importancia. Estaba integrada por cinco miembros -tres letrados y dos vecinos de buen juicio, costumbres y opinión-, un agente de Cámara, con las funciones de fiscal, y un letrado redactor, que tenía la función de relatar breve y sustancialmente las causas para acelerar el despacho. ${ }^{14}$ En un principio, eran nombrados cada bienio por el Gobierno superior, pero, al año siguiente, se estableció que todos los camaristas debían ser abogados y que durarían en su cargo mientras durara su buena conducta. ${ }^{15} \mathrm{~A}$ ellos se sumaban dos escribanos, cuatro procuradores, dos porteros y un alguacil de vara. ${ }^{16}$ Los camaristas y el agente estaban sujetos al juicio de residencia. El resto respondía a la Cámara, que tenía a su cargo el comportamiento y cumplimiento de las obligaciones, con conocimiento y facultad plena. Esto es, la superintendencia en toda la administración de justicia, la cual incluía la atribución de informar al cuerpo legislativo sobre las medidas necesarias para mejorarla.

El Congreso Constituyente, que en julio de 1816 había declarado la independencia, se trasladó a Buenos Aires en febrero de 1817 y dictó el 3 de diciembre un reglamento provisorio, cuya sección Iv estaba dedicada al Poder Judicial que residia "originariamente en la nación". No tendría dependencia alguna del Poder Ejecutivo Supremo y se regiría por las leyes de su instituto, en sus principios,

\footnotetext{
${ }^{13}$ Registro Nacional de la República Argentina, tomo 1, 1810-1821, Buenos Aires, La República, 1879, pp. 45-46.

${ }^{14}$ Reglamento de institución y administración de justicia del Gobierno Superior Provisional de las provincias del Río de la Plata. Supresión de la Audiencia y creación de la Cámara de Apelaciones, en Acuerdos y sentencias, tomo I, pp. 144-148. El asiento del Tribunal era el mismo que el de la Audiencia. Los magistrados debían mantener el equilibrio en los derechos de todo ciudadano por una administración de justicia breve y simple, pero con el menor margen de arbitrio, observando las reglas y providencias.

${ }^{15}$ Reglamento de administración de justicia, dado por la Asamblea General Constituyente de las provincias Unidas del Río de la Plata en la sesión del 1 de septiembre de 1813, en Registro Nacional de la República Argentina, tomo 1, 1810-1821, Buenos Aires, La República, 1879, pp. 230-232.

${ }^{16} \mathrm{Se}$ reemplazaron los jueces quedando los escribanos, procuradores y porteros que servian a la Real Audiencia. Corva, María Angélica, Constituir el gobierno, afianzar la justicia El Poder Judicial de la provincia de Buenos Aires (1853-1881), pp. 40-46.
} 
formas y extensión de sus funciones. Pero el director supremo estaba facultado para suspender a los magistrados con causa justa ante el Congreso. Si las causas de suspensión eran políticas, las resolvería por sí y, si eran de justicia, nombraría una comisión de fuera para determinar el mérito de la remoción. ${ }^{17}$

Entre 1810 y 1820, convivieron en la ciudad de Buenos Aires el cabildo y los gobiernos centrales, en un ambiente conflictivo, tanto por la naturaleza como por el origen de las instituciones. Ante el fracaso de conformar un poder central, los esfuerzos se concentraron en la unidad sociopolítica de la ciudad y su jurisdicción, convertidas en provincia soberana. ${ }^{18}$ En Buenos Aires, la construcción del Estado autónomo provincial comenzó formalmente el 11 de febrero de 1820, cuando el cabildo asumió el mando de la ciudad y su provincia, convocó al vecindario a cabildo abierto y se formó el 16 del mismo mes la Honorable Junta de Representantes. Al día siguiente, ésta designó gobernador a Manuel de Sarratea. La provincia tenía entonces su primera legislatura y su primer Poder Ejecutivo. ${ }^{19}$

Con la ley que suprimió los cabildos de Buenos Aires y Luján, el 24 de diciembre de 1821 , se fijaron las bases de la organización judicial de la provincia, que continuaba encabezada por la Cámara de Apelaciones, ahora con jurisdicción sobre la provincia, pero con jueces de primera instancia letrados, rentados e inamovibles. ${ }^{20}$ Por decreto del 5 de marzo de 1830, Juan Manuel de Rosas aumentó el número de los jueces de la Cámara de Justicia a siete, con dos fiscales - uno para lo civil y negocios de Hacienda y otro para lo criminal-, para poder formar dos salas.

El 8 de agosto de 1853, por decreto del gobernador Pastor Obligado, se redujo el número de camaristas a cinco. ${ }^{21}$ En 1854, el estado de Buenos Aires, separado de la Confederación Argentina, dictó su propia Constitución por la cual ejercía pleno derecho soberano en política interior y exterior, pero con las mismas bases doctrinarias de la Constitución nacional. El texto constitucional declaraba al Poder Judicial independiente en el ejercicio de sus funciones,

\footnotetext{
${ }_{17}$ Reglamento provisorio sancionado por el Soberano Congreso de las Provincias-Unidas de Sud-América para la dirección y administración del Estado mandado observar entre tanto se publica la Constitución, en Ravignani, Emilio, Asambleas constituyentes argentinas seguidas en los textos constitucionales, legislativos y pactos interprovinciales que organizaron politicamente la Nación, tomo 6, Buenos Aires, Talleres Jacobo Peuser, 1939, pp. 684-696.

${ }^{18}$ Goldman, Noemi, "Crisis imperial, Revolución y guerra (1806-1820)", en Noemí Goldman, Nueva Historia Argentina, Revolución, República, Confederación (1806-1852), Buenos Aires, Editorial Sudamericana, 2005, pp. 57-67

${ }^{19}$ Ternavasio, Marcela, "Construir poder y dividir poderes. Buenos Aires durante la 'feliz experiencia' rivadaviana", Boletín del Instituto de Historia Argentina y Americana Dr. Emilio Ravignani, núm. 26, segundo semestre, pp. 7-43.

${ }^{20}$ Corva, Maria Angélica, "El primer ensayo de organización judicial para el estado provincial de Buenos Aires (18211825)", en Justicias situadas. Instituciones, agentes, culturas y espacios (entre el Virreinato Rioplatense y la República Argentina, 1776-1864), La Plata, FAHCE-UnLP, 2018, p. 179-186.

${ }^{21}$ Registro Oficial del Gobierno de Buenos Aires de 1853, Buenos Aires, Imprenta de "El Orden", 1856, pp. 62-63.
} 
desempeñado por los tribunales y juzgados designados por la ley. Sus miembros no podían ser removidos sin causa y sentencia legal, pero eran suspendidos desde el momento que fueran enjuiciados.

La Cámara de Justicia fue reemplazada por el Superior Tribunal de Justicia, cuyos ministros eran nombrados por el gobernador a propuesta en terna del Senado. Requerían estar en ejercicio de la ciudadanía y ser mayores de 30 años, y haber pasado al menos seis en el ejercicio de la profesión. El Tribunal tenía "la Superintendencia en toda la administración de justicia" y podía informar al cuerpo legislativo de todo lo concerniente a las medidas convenientes para mejorarla. El texto constitucional atribuía el derecho a "cualquiera del pueblo" de acusar a los jueces por los delitos de cohecho, prevaricato, procedimientos injustos contra la libertad de las personas, contra la propiedad y seguridad del domicilio. 22

El pleno del Superior Tribunal debía formarse con al menos siete jueces y tenía a su cargo la superintendencia de toda la administración de justicia, que le confería la potestad para juzgar a los jueces inferiores y demás subalternos del Tribunal y otras atribuciones que tendían a conservar la moral y el orden de los juicios. ${ }^{23}$ El poder de superintendencia implicaba no sólo apercibir a los jueces por el incumplimiento de su deber, sino también, hasta la ley de enjuiciamiento, suspender, investigar y mandar a enjuiciar criminalmente a los acusados de faltas o delitos. ${ }^{24}$ Si bien era atribución ejercida por la Real Audiencia y la Cámara de Justicia, la diferencia al instalarse el Superior Tribunal fue su configuración constitucional como Gobierno judicial de un poder del Estado.

Una vez creada la Suprema Corte de Justicia, la Constitución provincial de 1873 debió establecer por resolución el alcance y jurisdicción de la superintendencia judicial. El texto de la providencia da luz sobre el significado de tal atribución y la necesidad de definirla expresamente.

La Constitución de 1873 organizó el Poder Judicial como una sección de la soberanía, independiente de las otras, dando a los magistrados que la forman garantías de independencia en el ejercicio de sus funciones. Pero esa independencia no podía ser absoluta sin caer en lo arbitrario: era necesario que, como la de los otros poderes, estuviese sometida al

\footnotetext{
${ }^{22}$ Artículos 125, 126 y 128 de la Constitución del Estado de Buenos Aires de 1854, Sección IV del Poder Judicial. El Superior Tribunal de Justicia fue organizado por la ley del 30 de septiembre de 1857 que determinaba su composición, atribuciones y el funcionamiento de la Alzada de Comercio. Registro Oficial del Estado de Buenos Aires de 1857, Buenos Aires, Imprenta de "El Orden", 1857, pp. 115-116.

${ }^{23}$ Diario de Sesiones de la Cámara de Senadores del Estado de Buenos Aires de 1857, Buenos Aires, Escuela de Artes y Oficios de la Provincia, 1890, p. 374.

${ }^{24}$ Causa ccxxvill, Acuerdos y Sentencias, tomo I, pp. 669-670.
} 
rígido imperio de las leyes orgánicas. Si ellas califican de delito o falta la transgresión que cometa un magistrado al ejercer sus funciones, él será justiciable ante el jury calificado que debe crearse según el artículo 190 de la Constitución. Pero desde que ese jury no se ha creado y organizado, no ha podido, lo que no existe aún, relevar el antiguo procedimiento de la superintendencia, cuyas atribuciones conserva el artículo 220, ínterin no se dicten las leyes orgánicas y reglamentarias, o cuando, aunque se hubiesen dictado y puesto en ejercicio aquellas leyes orgánicas, no se tratase de los delitos o faltas que la ley reservara al jury, sino de las medidas disciplinarias convenientes o necesarias que el artículo 158 autoriza a la Corte a establecer. ${ }^{25}$

\section{El caso Agrelo: prensa, opinión pública}

\section{$\mathrm{y}$ administración de justicia}

Pudimos observar la atribución del Máximo Tribunal de suspender, investigar y mandar a enjuiciar criminalmente a los magistrados, en la causa criminal contra el juez de primera instancia, Emilio Agrelo y otros, por delitos graves. El 28 de mayo de 1872, el ciudadano Ramón Posse dio el primer paso de este largo proceso, cuando publicó, en el periódico La Prensa, ${ }^{26}$ una denuncia contra el escribano Paulino Speratti por sustracción de depósitos judiciales del Banco de la Provincia, realizadas por orden del juez de primera instancia civil de la Capital, Emilio A. Agrelo. ${ }^{27}$ El 24 de marzo, había publicado en La Nación unos escritos referentes a la demanda promovida contra Agrelo, con motivo del dinero sustraído del juicio sucesorio a sus hermanos menores, denunciando el conocimiento que el juez tenía del robo de ese dinero, pues él había firmado las órdenes. Pero esos hechos escandalosos fueron relegados al olvido, esperando "que el tiempo gaste la impresión irritante que han causado en la conciencia pública”.

En la sección "Solicitadas", de La Prensa, Posse disculpaba a los miembros del Superior Tribunal, suponiendo que las denuncias anteriores no habían llegado a su conocimiento, dado el silencio guardado "en un asunto que tan vivamente afecta a la administración de Justicia”. Por la necesidad de que esos hechos llegasen a noticias del Tribunal, había resuelto llamar la atención todos los días

\footnotetext{
${ }^{25}$ Cita textual de la Resolución de la Suprema Corte, "Superintendencia judicial, su alcance y jurisdicción", Acuerdos y Sentencias, tomo I, p. 642.

${ }^{26}$ La Prensa, periódico fundado por J. C. Paz el 18 de octubre de 1869.

${ }^{27}$ La relación entre Paulino Speratti y Emilio Agrelo había surgido en el registro notarial (número seis) de la familia del magistrado. Durante 1871 y 1872, Francisco J. Fazio estuvo a cargo del Registro y Paulino Speratti fue adjunto.
} 
sobre la declaración del escribano Speratti, en presencia de Juan Carlos Ponce y Pedro Speratti, hermano del acusado. Aseguraba la sustracción de esos dineros en connivencia con el juez Agrelo, quien tenía gran parte de esa suma a su poder. Terminaba asegurando que, a partir de allí, el Superior Tribunal estaba en la obligación de sumariar o suspender al magistrado y él tenía el derecho de exigirlo. ${ }^{28}$ Así, Posse dejaba de manifiesto el conocimiento que tenía de su derecho constitucional y de las obligaciones del más alto Tribunal, en relación con la conducta de los jueces inferiores.

El mismo día, se reunió el Superior Tribunal y, en acuerdo extraordinario, rubricó la siguiente resolución, que nos permite conocer el procedimiento para iniciar la investigación a un magistrado:

Habiéndose publicado en el diario La Prensa de fecha de hoy en la página Solicitadas un artículo bajo el rubro Permanente en el que se denuncia un delito que se dice cometido por el doctor Agrelo en su carácter de juez de primera instancia, consignándose en el mismo datos bastantes para iniciar al efecto una investigación y llevando el mismo artículo una firma de persona conocida que lo garante, y siendo un deber del tribunal proceder a la formación de la sumaria respectiva para esclarecer un hecho que afecta directamente al buen nombre y crédito de la Administración de Justicia, -el mismo Superior Tribunal en acuerdo extraordinario ha resuelto que el señor vocal doctor don Sabiniano Kier proceda inmediatamente a la investigación respectiva, dando cuenta de su resultado, a cuyo efecto se agregará el diario mencionado. ${ }^{29}$

De esta forma, con una denuncia realizada no en forma directa al Tribunal, sino a través de un artículo periodístico, firmado por persona "que lo garante", se dio inicio a la investigación para esclarecer un hecho que afectaba a la administración de justicia. Para llevarla adelante, fue designado Sabiniano Kier, quien, al día siguiente, el 29 de mayo, inició el sumario llamando a declarar al hermano del escribano preso, Pedro Speratti.

Respecto a lo publicado en la prensa, Speratti expuso que era absolutamente falso, pues una sola vez había encontrado a Ramón Posse en la alcaldía de la cárcel $\mathrm{y}$, a pesar de que éste le había persuadido para declarar en contra de Agrelo, aseguró que "nada tenía que decir en contra del funcionario". Lo mismo

\footnotetext{
${ }^{28}$ La Prensa, 28 de mayo de 1872.

${ }^{29}$ Expediente por cuerda floja. "Indagación sobre el esclarecimiento de un hecho denunciado por Don Ramón Posse en un artículo publicado en el diario "La Prensa" bajo el rubro "Permanente" que dice cometido por el Dr. Don Emilio Agrelo en su carácter de juez", f. 2 y 2 v. (en adelante Denuncia de Posse).
} 
sucedió con Juan Carlos Ponce, quien afirmó no haber siquiera visto a Posse. Citado el denunciante, reconoció el artículo como suyo, ratificó la denuncia y agregó a Luis Lagos García para que lo llamaran a declarar.

El 30 de mayo de 1872, el vocal comisionado y el actuario Pedro Miliavaca se trasladaron a la alcaldía de la cárcel pública, para hacer comparecer a Paulino Speratti por el hecho denunciado en la publicación y la presunta declaración que había realizado frente a testigos. Contestó que la referencia que se hacía de él era falsa, pues, a pesar de haberle indicado Posse que declarara contra Agrelo, él "no se prestaría a declarar lo que era falso".

García Lagos era diputado provincial y no se podía llamarlo a declarar. Entonces, por orden verbal, Kier solicitó que se librara oficio al diputado, para que informara urgente por carta, dado su carácter de testigo presencial de los hechos denunciados. El mismo día, respondió que tenía parentesco en quinto grado civil con Ramón Posse y era su abogado en una causa contra Agrelo por cobro de pesos. Acusaba al juez de sustracción de un depósito judicial de sus hermanos Alberto y Dolores Posse, verificada por el escribano Speratti, con tres órdenes firmadas por el juez, cuyo total era de 210000 pesos.

Por pedido del preso Speratti, García Lagos había asistido a un encuentro con Ramón Posse en la alcaldía, en presencia de Pedro Speratti y Juan Carlos Ponce. Allí, el preso declaró "que él se reconocía culpable en los hechos que habían motivado su prisión, pero que más culpable era el doctor Agrelo". El condenado había entregado cantidades de consideración de los dineros sustraídos del banco a Agrelo, teniendo recibo de unos cuarenta o cincuenta mil pesos. Asimismo, el magistrado se había portado muy mal con él, pues, durante toda su prisión, no le había entregado más que veinte mil pesos para atender sus necesidades y las de su familia, estando sus bienes embargados. ${ }^{30}$

Dada por terminada la investigación, el 3 de junio, Kier elevó el expediente al Tribunal, el cual dio vista al fiscal Sixto Villegas. En su informe, aclaraba que, a pesar de que la denuncia contra Agrelo era extrajudicial, "el celo del Superior Tribunal encargó a Kier recoger los datos que hubiere sobre la denuncia a fin de fijar el procedimiento a que se debía dar lugar". Lo expresado en la prensa había quedado desvanecido por la declaración de los testigos como falsa referencia. Además, el parentesco de Lagos García con Posse y el hecho de ser su abogado quitaba toda fe legal a su informe. Por esto, Villegas indicaba dar por finalizadas las actuaciones, declarándose de conformidad los magistrados y dando fin a la causa. ${ }^{31}$

\footnotetext{
${ }^{30}$ Carta firmada por Luis Lagos Garcia. Denuncia de Posse, f. 6-7v.

${ }^{31}$ Denuncia de Posse, f. 9v.- $11 \mathrm{v}$.
} 
Por un lado, este episodio permite observar que el alto Tribual siguió haciendo uso de la atribución que la superintendencia le confería, y, por otro, determinar los pasos seguidos para la resolución del conflicto. Según el informe del fiscal, la denuncia era extraoficial, por lo cual había un procedimiento oficial, al que se ajustaba para rechazar la acusación. Esto fue posible gracias a la desestimación con base procesal de la declaración de Lagos y a la declaración del preso, firme en su defensa a Agrelo. Sin embargo, unos meses después, fue el mismo preso quien desató la tormenta.

A punto de ser trasladado a Patagones, para cumplir su sentencia de cuatro años de presidio confirmada en tercera instancia, Speratti recurrió a su última alternativa. Hizo publicar una carta en la prensa, denunciando la complicidad de Agrelo. Antes de introducirnos en el proceso iniciado por el condenado, y para comprender la relación entre administración de justicia y opinión pública, analizaremos los cambios que la prensa había comenzado a sufrir en esos años, no sólo en relación con la tecnología y las formas, sino a su función en la sociedad. ${ }^{32}$

El espacio público en Buenos Aires tuvo su origen en el proceso de construcción del nuevo Estado, con una extremada fragilidad durante la primera mitad del siglo, debido a los conflictos políticos que la revolución había iniciado. A pesar de su declarado valor, en la práctica, la divulgación de los actos públicos y la libertad de pensamiento y expresión eran sistemáticamente violadas. ${ }^{33}$

A partir de 1852, la vida pública de Buenos Aires pasó por un proceso de renovación y de ampliación, reflejado en la expansión de la prensa, pues los sectores políticos la utilizaban para "interpelar, modelar y orientar" una creciente e influyente opinión pública. ${ }^{34}$ En Iberoamérica, surgieron nuevas formas de sociabilidad, que basaban su legitimidad no en la costumbre o en la ley, sino en la voluntad de los asociados. ${ }^{35}$ El objetivo de la prensa de esos años era la discusión, aunque también informaba. Por lo mismo, a lo largo del siglo XIx,

\footnotetext{
${ }^{32}$ Entendemos "opinión pública" en el sistema republicano como "uno de los pilares de la legitimación del poder fundado sobre la soberanía popular, que remitía básicamente a la potestad del pueblo para "opinar", evaluar y juzgar la actuación del gobierno durante el ejercicio de su mandato". SÁBATO, HILDA, "Los desafíos de la república. Notas sobre la política en la Argentina pos Caseros", Estudios Sociales, año 24, núm. 46, pp. 77-117.

${ }^{33}$ MYERS, JORGE, Orden y virtud. El discurso republicano en el régimen rosista, Argentina, Universidad Nacional de Quilmes, 1995, p. 26.

${ }^{34}$ LemTIERI, Alberto, La construcción de la República de la opinión, Buenos Aires frente al interior en la década de 1850, Buenos Aires, Prometeo Libros, 2006, pp. 252-264.

${ }^{35}$ Sábato, HILDA, Ciudadanía política y formación de las naciones. Perspectivas históricas de América Latina, México, Fondo de Cultura Económica, 1999, pp. 25-26.
} 
la prensa fue ámbito de debate público y forma de hacer política, de modo que estimulaba la formación de una "moderna opinión pública". ${ }^{36}$

La etapa que finalizó en 1870 ha sido definida como intermedia o de transición de una metamorfosis asombrosa, donde confluyeron factores técnicos, económicos y sociales generados en el marco del Estado liberal. En el plano teórico, este Estado reconocía a la libertad de expresión como uno de sus principios rectores, considerando al periodismo como el órgano natural por medio del cual ese derecho se ejercitaba y se volvía efectivo. ${ }^{37}$ Fue así como Posse utilizó esta prensa política -con la función de denunciar los problemas por los cuales pasaba la administración pública y como medio de ejercer el derecho de expresarse-, para hacer públicos los actos de corrupción en la justicia, mientras Speratti la empleó como soga de ahogado, para aminorar sus años de encierro.

El redactor del periódico La Pampa, quien aceptó publicar la carta del desesperado condenado, la antecedió de una nota en primera plana con el título "Tremenda acusación”, dedicada fundamentalmente a explicar por qué había admitido una solicitada, que publicaba un escribano condenado a presidio contra un juez de primera instancia. Según sus palabras, tres eran los objetivos de tal publicación. Primero, que el acusador presentara a los tribunales su denuncia y las pruebas para sostenerla. Segundo, que lo que se murmuraba en los corrillos se volcara en una hoja impresa para depurarse de las calumnias u ofrecer la verdad. Tercero, que el funcionario acusado supiera de qué se lo acusaba y pudiera en las columnas del mismo diario "defenderse enérgicamente ante el pueblo a quien sirve y que lo sostiene, y llevar ante el jury al que lo acusa, para que su reputación salga limpia e ilesa como ha salido de la prueba, la de un juez que acaba de ser absuelto por el jurado del pueblo". ${ }^{38}$

Los propósitos planteados determinaban la preeminencia de la prensa por sobre la administración de justicia en este tipo de conflictos, definiendo como jury al alto "Tribunal del pueblo", responsable de condenar las faltas graves de un magistrado o permitirle que salve su reputación personal y profesional.

El caso de Agrelo le permitía a Paz demostrar que la prensa cumplía una función necesaria, debido a un conflicto más profundo que sufría la sociedad de la provincia de Buenos Aires. La administración de justicia padecía de una

\footnotetext{
${ }^{36}$ Alonso, Paula, Construcciones impresas. Panfletos, diarios y revistas en la formación de los Estados Nacionales en América Latina, 1820-1920, Buenos Aires, FCE, 2004.

${ }^{37}$ Pasqual, Patricia, "El periodismo (1852-1914)", en Nueva Historia de la Nación Argentina, La configuración de la República independiente, 1810-1914, tomo 6, Buenos Aires, Academia Nacional de la Historia - Planeta, 2000-2001, pp. 489-534.

${ }^{38}$ Diario La Pampa, domingo 29 de diciembre de 1872, año 1, núm. 77, Imprenta y oficina de la redacción Victoria 79. Director y redactor Ezequiel N. Paz (creó el periódico cuando dejó La Prensa).
} 
"enfermedad interna, crónica, gangrenosa”, que requería de grandes remedios, incluyendo la renovación de todos los magistrados, y que el Gobierno no se había atrevido a aplicar. Uno de los problemas era que "los jueces se juzgan ellos mismos recíprocamente, y el espíritu de cuerpo y el encadenamiento de afecciones y la solidaridad de las culpas y de los errores tienen que ejercer presión sobre los que juzgan a sus mismos colegas o a sus superiores o inferiores".

El cuadro planteado era desolador y, para el editor, la solución estaba en la opinión pública, pero también en la modificación del sistema de juzgamiento de los magistrados. Este tema fue luego uno de los más conflictivos en los debates que se generaron en la Convención Constituyente y terminó con la organización de un jury calificado, compuesto de legisladores letrados, como veremos más adelante.

El escribano Speratti se había mantenido firme en su negativa de haber sustraído los fondos judiciales en connivencia con el juez Agrelo. Pero los días pasaban y, cuando llegó el momento en que dejaría la cárcel de Buenos Aires para ser trasladado al presidio de Patagones, se terminó el silencio. Recurrió a la prensa para denunciar a su cómplice en un extenso y detallado artículo, en el cual reconocía haber faltado "a los deberes sagrados" propios de su oficio. Asimismo, argüía que no había dispuesto de los depósitos sustraídos, limitándose a una criminal condescendencia, justificada por su juventud, su inexperiencia y la fascinación por un hombre que le había propuesto ser su protector y mejor amigo, con el objeto de hacerlo instrumento de sus maldades. ${ }^{39}$

Speratti justificaba su silencio afirmando que ese hombre se le había presentado de rodillas en la cárcel para pedirle que lo salvara, luego, él, con sus relaciones e influencias lo libraría de toda culpa y cargo. Creyendo en la palabra de Agrelo, había sido consecuente y leal con su promesa, pero él lo había engañado y por eso lo acusaba ante el Tribunal y la opinión pública. En su desesperación, definía a la opinión pública como "ese severo e incorruptible jurado, que, por razón ni consideración alguna, tuerce sus fallos, que jamás dicta sus sentencias contra los más débiles, sino contra los verdaderos culpables, por más encumbrada que sea su posición, y mucha su influencia”.

Demostró con una minuciosa enumeración de sus antecedentes que había merecido la estimación pública por su intachable conducta, hasta que un día Agrelo lo llamó y le dijo “que se encontraba arreglado con los interesados de la testamentaria de Idarragovi para sacar del banco cincuenta mil pesos $\mathrm{m} / \mathrm{c}$

${ }^{39}$ La Pampa, domingo 29 de diciembre de 1872, año 1, núm. 77. Manifestación que hace el exescribano Paulino R. Speratti, con motivo del proceso que se le ha seguido sobre sustracción de depósitos judiciales. (en adelante $L a$ Pampa). 
que necesitaba con urgencia porque había perdido doscientos mil pesos en el Club del Progreso y que no tenía más que ciento y tantos mil pesos”. Con la debilidad de acceder a su pedido, sacó el dinero del banco, dinero que Agrelo nunca le devolvió, obligándolo a realizar otras sustracciones, "que resultan de los decretos que existen en mi poder, de los oficios y las constancias que de esas extracciones existen en el banco".

Una vez que estuvo en prisión, le prometió su ayuda a cambio de silencio "porque, aunque él tenía muchas suciedades, los viejos pillos del Tribunal tenían más que él y lo tenían que respetar". Pero la entrega de los depósitos se dilataba y tampoco le buscaba un defensor entre los abogados conocidos, por lo cual eligió a Matienzo, quien no utilizó los decretos firmados por Agrelo para su defensa. ${ }^{40}$ Según Speratti, la formación del sumario no fue prolija, porque se trataba de "un pobre diablo y escribano sinónimo de pillo y explotador". Ante este panorama, confiaba en que el público pensara diferente que los togados, no aceptando que la firma de diecinueve decretos para extraer fondos judiciales se arrancara por sorpresa a un juez como Agrelo.

Todas estas declaraciones no cayeron en saco roto, como en la primera oportunidad, sino que abrieron las puertas a la investigación y al juicio. El 2 de enero de 1873, los miembros del Superior Tribunal resolvieron iniciar el proceso; asignaron a uno de sus magistrados para que llevara adelante la investigación, con el objeto de confirmar la veracidad de la denuncia realizada por Speratti. De confirmarse, Agrelo sería enjuiciado por un juez del crimen. Entre tanto, el juez de primera instancia en lo civil, Emilio A. Agrelo, estaba suspendido ${ }^{41} \mathrm{y}$ el Tribunal decidió reasignar las causas que tramitaban en su juzgado. ${ }^{42}$ Otra vez, el detonante fue la denuncia en la prensa.

Habiéndose publicado en el diario La Pampa de fecha veintinueve de diciembre del año anterior, un artículo denunciando delitos imputados al doctor Agrelo en su carácter de juez de primera instancia,

\footnotetext{
${ }^{40}$ Cuando Speratti reclamó a Matienzo, éste respondió que no utilizó los recibos de los depósitos "por temor al doctor Agrelo, que lo habría sacrificado, y que él tenía hijos y que Agrelo como juez podía perjudicarlo en los asuntos que él como abogado tenía en el Juzgado de aquél".

${ }^{41}$ La suspensión del magistrado ordenada por el Superior Tribunal tiene su resolución para nuestro sistema judicial en la Ley 14.441 de 2012, que introdujo en el régimen de enjuiciamiento de magistrados de la provincia de Buenos Aires la figura del apartamiento preventivo.

${ }^{42}$ Acuerdo extraordinario del 9 de enero de 1873. Acuerdos y sentencias, tomo I, p. 552. "Que estando suspendido el juez de primera instancia en lo civil doctor don Emilio A. Agrelo, y debiendo por tal causa arbitrarse un medio legal que remedie los inconvenientes de la paralización de las causas que tramitan por ese juzgado, debian mandar y mandaron, que en aquellas en que actué el secretario don Natalio Ponce conozca el juez doctor don Miguel García Fernández, en las del secretario don Félix Sagasta el doctor don Jorge Echeverría, en las del de igual clase D. Leandro García el doctor don Honorio Martel, y en las del secretario don Manuel Malmierca el doctor don Luis Beláustegui".
} 
consignándose datos y ofreciéndose justificativos cuya existencia e importancia es necesario investigar: siendo un deber del Tribunal de Justicia proceder a la indagación respectiva, para esclarecer hechos que tan profundamente afectan el crédito de la Administración; el mismo Superior Tribunal, reunido en acuerdo extraordinario, ha resuelto que el señor vocal don Tomás Isla proceda inmediatamente a esa investigación, dando cuenta con toda brevedad de su resultado. Líbrese oficio al Poder Ejecutivo para que a los efectos expresados suspenda la remisión del preso Speratti a Patagones hasta nueva resolución y agréguese el periódico a que se hace referencia. ${ }^{43}$

El escándalo repercutió en la prensa de la campaña; el semanario El Monitor de la Campaña, en Capilla del Señor, cabecera del partido de Exaltación de la Cruz, ${ }^{44}$ el 26 de enero de 1873, publicó un artículo titulado "Asunto Speratti”. ${ }^{45}$ El editor expuso los pormenores del caso y se explayó respecto a los diarios de la capital. En su mayoría, éstos se habían limitado a discutir sobre los procedimientos por seguir, "recordándonos una vez más que Buenos Aires es antes de todo una ciudad de doctores”. Defendía al periódico La Pampa, acusado "de hacer un negocio mercantil con esa ruidosa cuestión”. Aprovechó para exponer las necesidades que sufría la campaña, "víctima de esos robos que preocupan hoy el espíritu público; la distancia, la ignorancia de las tramitaciones, todo contribuye para que la campaña sea una presa fácil para los jueces prevaricadores, los abogados y los escribanos sin conciencia”. Esperaba que Agrelo fuera inocente y comprendía la posición dolorosa por la cual estaba pasando, pero había estallado la indignación popular contra los defectos de la administración a la que pertenecía. Si hubiera salido inocente, habría sido una de las víctimas que pisaban la revolución en su carrera desordenada.

Volviendo al proceso, el primer paso que dio Tomás Isla ${ }^{46}$ fue llamar a declarar a las personas que tuvieron conocimiento de los hechos mencionados en el

43 "De la causa criminal que se sigue al doctor Agrelo y otros por extracciones indebidas de depósitos de Banco", Archivo Histórico de la provincia de Buenos Aires, Juzgado del Crimen (en adelante Causa Agrelo).

${ }^{44}$ El partido de Exaltación de la Cruz y su cabecera, Capilla del Señor, está ubicado en el centro noreste de la provincia, a $83 \mathrm{~km}$ de la capital. En 1785, fue nombrado alcalde de hermandad Francisco Casco y en 1822 juez de paz Justo Fonseca. En 1856, se instaló la primera municipalidad de elección popular. En 1881, el partido tenía una población absoluta de 6299 habitantes, de los cuales 2514 vivian en el pueblo. La provincia tenía una población absoluta de 526581 habitantes.

${ }^{45}$ El Monitor de la Campaña, año 3, núm. 85, domingo 26 de enero de 1873. Editor Salvador Cruz.

${ }^{46}$ Tomás Isla fue juez del crimen del Departamento del Norte entre 1862 y 1866 . Ese año fue removido a juez comercial de la capital y ocupó ese cargo hasta 1872. El 2 de noviembre de 1872, pasó a ser miembro del Superior Tribunal. Registro Oficial de la provincia de Buenos Aires, 1866, p.33-34 y 1872, p. 447. Con las reformas posteriores a la Constitución de 1873, Isla fue designado presidente de la Cámara criminal y comercial del Departamento Capital el 27 de octubre de 1874. Fue nombrado Procurador de la Suprema Corte con acuerdo del Senado por decreto del 20 de octubre de 1880. 
artículo de Speratti, inserto en el expediente. El mismo día de su designación, hizo comparecer al denunciante - que se hallaba en la cárcel pública- en una de las salas del Superior Tribunal de Justicia. Éste confirmó que había mandado publicar el artículo que llevaba su firma, ratificando su contenido. Respecto a los documentos que según el artículo estaban en su poder, se excusó diciendo que los tenía una persona de su confianza que se encontraba fuera de la ciudad.

En numerosas oportunidades, el mismo Agrelo se los había solicitado, y era él mismo quien le había enviado a su defensor Agustín Matienzo. A lo dicho en el artículo, agregó que Juan Francisco Font le había comunicado que Agrelo había recibido del juez de paz de Areco fondos de la testamentaria de Donohé, de lo cual tenía recibo. Isla pidió que se trajeran a la vista esa sucesión y la de Monteverde.

A continuación, comparecieron los alcaldes de la cárcel pública, Nicolás Leguizamón y Mariano Espinosa, y fueron interrogados sobre la cita que Speratti hacía en el artículo. Ambos coincidieron en que Agrelo había ido varias veces a ver al preso, y que, por ser miembro de la administración de justicia, se le permitía que se entrevistaran a solas, en una oficina interior de la alcaldía. Espinosa agregó que "una vez que pasaba por el cuarto" vio que el magistrado le entregaba al preso una cantidad de dinero. Los llaveros también fueron interrogados, pero dijeron que no conocían a Agrelo. ${ }^{47}$

Isla mandó a intimar a los escribanos Francisco Fazio y Albano Honores, quienes entregaron en el mismo día los autos testamentarios de Monteverde y de Donohé para que se agregaran a esas actuaciones. El escribano Naviera, también mencionado en el periódico, confirmó lo dicho sobre el cobro que había realizado Agrelo durante la feria, de los intereses de la testamentaria de Santiago Donohé, resultado de una venta de ovejas en San Antonio de Areco, que no figuraban en el expediente.

En cuanto al defensor Agustín Matienzo, negó todo lo que dijo Speratti y afirmó que éste le había suplicado reiteradas veces que se hiciera cargo de su defensa, por lo cual fue contratado en una reunión que tuvo en la alcaldía con él, su hermano y su esposa, Casilda Villamayor. El escribano no quería complicar a Agrelo, pero, una vez dictada su sentencia, le pidió nuevamente su defensa, mostrándole sólo algunos decretos de depósitos mandados a extraer por Agrelo. Le pidió que fuera a verlo para que realizara un informe. En el expediente, el defensor presentó cuatro cartas que le había mandado Speratti entre abril y octubre de 1872, explicándole que no quería ver más a Agrelo, que no le había mandado dinero. Le pedía que le entregase los documentos a su hermano y le

\footnotetext{
${ }^{47}$ Causa Agrelo, f. 6.
} 
ofrecía garantir sus honorarios con sus bienes, pues estaba tan pobre que no tenía ni para cubrir las obligaciones apremiantes de su familia. ${ }^{48}$

Las declaraciones de Adolfo Insiarte y Miguel Villegas, director de los albaceas de la testamentaria, confirmaron la extracción indebida de fondos, aun cuando se resistieran al procedimiento. Lo mismo sucedió con Juan Francisco Font, que confirmó la apropiación de los depósitos por parte de Agrelo, escudado en dilaciones y equivocaciones involuntarias. Compareció entonces Ramón Posse y expuso que, cuando supo que el depósito de 310000 pesos pertenecientes a sus hermanas había sido extraído del Banco de la Provincia, dio los pasos necesarios para averiguar quién lo había hecho. Lo mismo hizo Miguel Esteves para el depósito de 100000 pesos, pertenecientes a la testamentaria de Avalos. Ambos casos, habían sido autorizadas por Agrelo y ejecutadas por Speratti.

Espontáneamente, se presentó el juez Agrelo y expuso que "habiendo leído el libelo publicado por el escribano Speratti”, se veía obligado a buscar su completo esclarecimiento. Sabiendo que Isla había sido designado para la investigación le pedía, primero, que solicitaran a Speratti los documentos a que se refería, es decir las solicitudes para extracción de dinero con el decreto puesto al pie de ellas y las notificaciones respectivas; segundo, que se mandaran traer las testamentarias de Donohé y Monteverde en las que se encontraba la verdad de los hechos; tercero, que sobre todas las denuncias del libelo se examinara a Fazio, exsocio de Speratti. El deponente estaba pronto a todas las declaraciones que solicitara el camarista.

El magistrado a cargo de la investigación pidió al Banco de la Provincia el informe sobre la cantidad que se depositó en ese establecimiento. También solicitó el detalle en orden cronológico de las extracciones hechas a las testamentarias de Santiago Donohé y de Santiago Monteverde, especificando a favor de quién se hicieron. El escribano Honores presentó los autos testamentarios de Monteverde, con siete incidentes y faltando las fojas de 8 a 11 y de 267 a 294. Luego de ser apercibido, Fazio entregó los autos de Donohé. Pero Speratti seguía sin entregar los documentos ofrecidos porque quien los tenía no había regresado a la ciudad

Entretanto, Isla se dirigió al cónsul de Francia, por su carácter de infrascrito del Superior Tribunal, quien lo condujo a Julio Jonás. Éste era el encargado de las testamentarias de los ciudadanos franceses, por lo cual se le tomó declaración el 7 de enero. Jonás explicó que, en los autos testamentarios de García Turuella y de José Guignes, se omitió el depósito en el banco, entregado al escribano

\footnotetext{
${ }^{48}$ Causa Agrelo, fs. 7-10.
} 
Fazio por los señores Mantalen y Cía. Declaró que, en una reunión con Agrelo, éste le aconsejó no dar paso alguno por ocho días, para no demorar el proceso a Speratti, pues convenía la terminación breve para que éste reintegrara los fondos. Ante la falta de respuestas por la vía informal, presentó un escrito denunciando la falta de los depósitos.

Cuando el Banco de la Provincia presentó los informes, el 8 de enero de $1873,{ }^{49}$ Isla dio fin al proceso sumarial y decidió que estando terminadas las diligencias de investigación se elevase al Superior Tribunal. Miliavaca las elevó con las causas agregadas ese mismo día. El Tribunal resolvió que había mérito suficiente para enjuiciar a Agrelo, quien quedaba suspendido en el ejercicio de sus funciones. Se mandó al juez del crimen, Joaquín Cueto, que inmediatamente procediera a instruir el proceso, y que le diera prioridad a esta causa, habilitando días festivos y horas. Asimismo, se le ordenó dar cuenta de los avances del proceso al Tribunal cada cuatro días. ${ }^{50}$

Agrelo fue notificado; se pasó oficio al Poder Ejecutivo y, el 8 de febrero, el ministro de Gobierno, Amancio Alcorta, acusó recibo de la nota del Superior Tribunal, informando la suspensión del magistrado sin goce de sueldo hasta nueva resolución. Al día siguiente, el juez Cueto recibió el expediente, con las dos sucesiones e incidentes, y mandó proceder a la formación del sumario, según lo ordenado por el Superior Tribunal. Con ello, terminaba el proceso administrativo y se iniciaba la causa penal.

Si bien no contamos con todo el proceso judicial allí iniciado, sabemos que fue muy extenso, pues existen dos cuerpos de 500 fojas. Pudimos acceder a la resolución porque Agrelo recurrió a la Suprema Corte, y el Acuerdo del 6 de abril de 1878 contiene una sintesis de la causa. La primera sentencia fue dada por el juez Cueto, el 31 de enero de 1874, donde condenó a diverso tiempo de prisión al exjuez doctor Agrelo y a los escribanos Fazio y Echanagucia. Agrelo tuvo cinco años de prisión e inhabilidad para cargo público y los escribanos, la privación de oficio. Todos fueron obligados a las responsabilidades civiles con arreglo a los hechos declarados y a las costas en las proporciones designadas. La sentencia de primera instancia estableció la criminalidad de Agrelo en los hechos que expresaba y, en otros, "la negligencia, la sospechosa indolencia, la responsabilidad penal, que clasifica la culpabilidad, usando las palabras de la ley primera, título 31, parte 7".

Apelada la sentencia de primera instancia, el 15 de junio de 1877, la Cámara del Crimen derogó el delito de hurto de Agrelo, pero confirmó su

\footnotetext{
${ }^{49}$ Causa Agrelo, fs. 42-45.
}

${ }^{50}$ Causa Agrelo, fs. 45 v- 46 . 
culpabilidad, disminuyendo la condena. El fallo no fue unánime, Lorenzo Torres no encontró culpa alguna; Tomás Isla acusó omisiones que lo hacían punible por faltas graves y Luis Lagos García halló conducta culpable, culpabilidad punible y grave culpabilidad..$^{51}$ La sentencia de culpabilidad de faltas graves quedó compurgada por la prisión e inhabilidad sufridas. Como puede observarse, en esta instancia de apelación, reaparecen dos abogados que formaron parte del proceso, en nuevas funciones, después de las reformas surgidas del nuevo texto constitucional.

También se apeló a esta sentencia y el recurso de inaplicabilidad de ley interpuesto ante la Suprema Corte fue fallado improcedente el 11 de abril de 1878. Ello tuvo como fundamento que, en la segunda instancia, los tres jueces votaron de acuerdo, en cuanto a la carencia de criminalidad del exmagistrado, pero no acordaron en cuanto a las responsabilidades penales. ${ }^{52}$ La sentencia revocó la criminalidad imputada y penas impuestas, dando por compurgada la culpabilidad de faltas graves con la prisión e inhabilitación sufrida. Entonces, en las sentencias de primera y segunda instancia, la culpabilidad punible era un hecho declarado, que debía fundarse en los modernos Códigos de Perú, Chile y España, los cuales constituían la doctrina. Asimismo, la culpabilidad debía basarse en los artículos 190 al 194 de la Constitución, "refiriéndose expresamente al proceder punible de los magistrados judiciales en el ejercicio de sus funciones".

El caso Agrelo comenzó el año que la Convención Constituyente debatía el enjuiciamiento de los magistrados y finalizó el año que se sancionó su legislación. Por lo mismo, es representativo, para dimensionar la transformación que se estaba gestando desde un juzgamiento entre pares hacia la conformación de un jurado de enjuiciamiento.

\footnotetext{
${ }^{51}$ Sólo Isla era magistrado de la Cámara. Torres y García eran conjueces que actuaban en caso de impedimento o recusación de los miembros. Los magistrados eran reemplazados por abogados sacados a la suerte de una lista de treinta, de la matrícula que formaba cada año el Tribunal. Eran jueces estables durante ese año en los impedimentos o recusaciones. Acuerdos y sentencias, I, p. 607-608.

${ }^{52}$ El recurso de inaplicabilidad de ley es una atribución de la Suprema Corte establecida por el texto constitucional provincial de 1873. El máximo Tribunal "conoce en consulta, o en grado de apelación, de las causas en que se imponga la pena capital, al solo efecto de decidir si la ley en que se funda la sentencia es, o no, aplicable al caso, siendo necesario unanimidad para declarar aplicable la ley". Malaver, Antonio, Curso de procedimientos judiciales en materia civil y mercantil, Buenos Aires, Imprenta de Pablo E. Coni, 1875, pp. 131-132.
} 


\section{El enjuiciamiento de magistrados en la Constitución de 1873 y su legislación}

La conformación de un sistema judicial, a través de la carta constitucional para la provincia de Buenos Aires, obligó a los constituyentes a preguntarse de quién emanaba el poder encargado de administrar justicia, si emanaba de los otros poderes o del pueblo, directamente. La respuesta a esta pregunta requería afinar el concepto de soberanía y el de su ejercicio, aunque se le quisiera dar a la elección en segundo grado un perfil práctico, basado en la falta de capacidad del pueblo elector para discernir sobre la idoneidad, inteligencia y honorabilidad de los jueces..$^{53}$ Pero, en medio de la discusión, quienes se posicionaban por una $\mathrm{u}$ otra posibilidad, fundamentalmente, buscaban responder a la garantía de justicia. Unos consideraban la libertad de la sociedad civil para elegir quién la impartiría y, otros, que ese acto fuera realizado por quienes, a su entender, tuvieran aptitud para ejercerlo. En ambos casos, esa garantía iba siempre relacionada con la responsabilidad del magistrado en su función jurisdiccional.

En cambio, cuando se discutió la duración en el cargo, la opción por la inamovilidad buscó garantizar a todos la independencia del juez por la duración de su empleo, mientras respondiera a la confianza depositada en él. Esto requería de un jurado específico para juzgar al magistrado en ejercicio y el camino hacia su conformación significó diferenciar entre juicio político y enjuiciamiento a cargo de un jury, determinado por el grado de responsabilidad de quienes ejercian la magistratura. ${ }^{54}$

En el fragor de los debates, se llegó a plantear la utilidad del jury, pero, una vez aceptado, debió definirse su conformación. Para unos, la opción de integrarlo con letrados del cuerpo legislativo representaba una garantía para el juez y, para otros, un "pararrayos" sobre los Tribunales. La buena conducta era el límite de la inamovilidad del juez, pero, cuando ese límite se pasaba, cualquiera del pueblo podía acusarlo, y serían legisladores letrados quienes

\footnotetext{
${ }^{53}$ El ejercicio intelectual de pensar al soberano debía definir qué papel darle sin poner en riesgo el control del orden social. Bonaudo, Marta y SonzogNI, ÉlIDA, "Los grupos dominantes entre la legitimidad y el control", en Marta Bonaudo (dir.), Nueva Historia Argentina. Liberalismo, estado y orden Burgués (1852-1880), tomo 4, Buenos Aires, Editorial Sudamericana, 1999.

${ }^{54}$ Actualmente, la Corte Suprema de la Nación ha definido la función de los tribunales de enjuiciamiento, que no tienen carácter judicial ni tampoco sus órganos son administrativos, sino que solamente ejercen atribuciones de tipo político atinentes a la responsabilidad de los jueces (Fallos: 302.934, La Ley, 1980-D, 320). Se persigue solamente la destitución del magistrado, el cual será luego sometido a juicio ordinario, si corresponde, ante un tribunal judicial. Brianti, Susana Alicia, El jurado de enjuiciamiento de magistrados y funcionarios de la Provincia de Buenos Aires y la Suprema Corte de Justicia. Facultades, Buenos Aires, La Ley, 2008.
} 
determinaran su incompetencia o inconducta. ${ }^{55}$ Esta discusión implicó la valoración de la función del abogado en el cumplimiento de las garantías para el juez, como los debates sobre la libre defensa y representación fueron para las garantías del ciudadano.

En los proyectos previos al debate constitucional, el enjuiciamiento de los magistrados incluía varios artículos que sufrieron numerosos cambios, desde el proyecto de la comisión Poder Judicial y el de la comisión central hasta el texto definitivo. El convencional José María Moreno expuso las razones por las cuales debía implementarse el enjuiciamiento de los magistrados. El respeto y la consideración que se debía a la magistratura exigía un jurado encargado de resolver y decidir en las faltas y delitos cometidos por los magistrados, en el ejercicio de sus funciones, como garantía de elevado carácter, de perfecta imparcialidad y de reconocida competencia.

No eran delitos o actos de los criminales ordinarios los que un juez haría en el ejercicio de su puesto. Si violaba las leyes especiales de procedimiento, se requería de una persona constituida en autoridad para apreciar los hechos de ese magistrado, y con perfecto conocimiento del derecho para declarar si había sido o no culpable. Por esta razón, se formó un jury con letrados. Para que éste garantizara rectitud y severidad imparcial, se agregó que fueran del cuerpo legislativo, esto mantenía la misma soberanía popular sin afectar la jurisdicción del juicio político. ${ }^{56}$

Muy distinta era la visión de Miguel Navarro Viola, para quien las cámaras y tribunales inferiores debían ser denunciados por cualquier habitante de la provincia, pues nadie mejor que el mismo damnificado estaría en condiciones de hacerlo. Proponía que el jury fuera presidido por un abogado y que cualquiera del pueblo pudiera denunciar a miembros de cámaras y tribunales inferiores, por delitos cometidos en el ejercicio de sus funciones, pues era diferente la responsabilidad de acusar y de denunciar.

En cambio, para Juan José Montes de Oca, la denuncia hecha por cualquiera del pueblo tendría un efecto más extenso, igual que para José Manuel Estrada, porque los integrantes del jury debían ser letrados y la garantía de todo Gobierno libre era la igualdad ante la ley, para los débiles y para los fuertes. El hecho de ser diputado o senador no constituía a un hombre perito

\footnotetext{
${ }_{55}$ ParRy, Adolfo, Responsabilidad de los Magistrados de la provincia de Buenos Aires, La Plata, Taller de Impresiones Oficiales, 1923.

${ }^{56}$ Debates de la Convención Constituyente de Buenos Aires, 1870-1873. Publicación Oficial hecha bajo la dirección del convencional Luis V. Varela, reimpresión con índice alfabético y cronológico confeccionado por Adrián Becar Varela, La Plata, Taller de Impresiones Oficiales, 1920 (en adelante DCC), 27 de junio de 1873, pp. 1229-1230.
} 
en la ciencia del derecho, lo cual ponía a los jueces de los tribunales en peor condición que al último ciudadano. ${ }^{57}$

La insistencia de que fueran abogados los que juzgaran los actos de los jueces se manifestó en el discurso de Antonio Malaver, pues consideraba que, de no ser así, se aceptaba una violación de la tramitación y una falta en la aplicación del derecho. Para quienes defendían esta postura, los jueces y los abogados eran los únicos capaces de juzgar y condenar a otros jueces, porque el común de los hombres contaba sólo con la inducción, que no bastaba para averiguar si un juez había faltado o no a la ley. Para quienes estaban en contra, la condición de ser abogados para los miembros del jury, en lugar de ser una garantía, determinaba que, a su amparo, hubieran podido contar los jueces con la impunidad en los delitos que cometiera. Los vínculos entre el acusado y los jueces serían una "especie de pararrayo que se quiere levantar sobre cada uno de los tribunales para que los jueces puedan contar con la impunidad del delito que lleguen a cometer por espíritu de compañerismo". ${ }^{58}$

A pesar de estos argumentos, y con el apoyo de Navarro Viola, de Estrada y de Pereyra, el jury fue finalmente conformado con siete diputados y cinco senadores profesores de derecho y el resto de los artículos fueron aprobados por unanimidad. En algunos casos, cambió parte del texto; sin embargo, quedaba establecido el primer antecedente de jurado de enjuiciamiento en Argentina.

Una vez que se definió el enjuiciamiento de magistrado en el texto constitucional, se requirió de una ley para que la institución fuera instalada, reglamentada y puesta en funcionamiento. Lo interesante, y al mismo tiempo fundamental, de seguir estos debates es que nos permite observar y analizar las cuestiones que quedaron sin resolver en la urgencia y la necesidad política de promulgar una carta constitucional provincial. Para dimensionar el tiempo que llevó la sanción de la ley, es útil trazar su itinerario, antes de adentrarnos en los debates.

El primer paso fue la presentación de un proyecto de Luis Vicente Varela, en marzo de 1876, sin embargo, pasó a la agenda política del año siguiente. El debate comenzó en la Cámara de Diputados, el 24 de octubre de 1877, y se extendió a varias sesiones. El proyecto aprobado pasó a la Cámara de Senadores y fue tratado, el 16 de julio de 1878. En el debate, se presentó en paralelo el proyecto sancionado en la Cámara de Diputados y las modificaciones propuestas por la Comisión de Negocios Constitucionales de Senadores. El 8 de octubre de 1878, en la Cámara de Diputados, se trató la aceptación de las

\footnotetext{
${ }^{57}$ DCC, 1 de julio de 1873, pp. 1233-1235.

${ }^{58}$ DCc, 4 de julio de 1873, pp. 1245. Estas palabras pertenecen al convencional Mariano Marín, que era abogado.
} 
modificaciones propuestas por la de senadores, y la ley fue sancionada, el 12 de octubre de 1878 .

El 23 de octubre de 1877, el presidente de la Cámara de Diputados declaró cerrada la sesión legislativa de la Cámara y ésta se constituida ésta en comisión para ocuparse de los proyectos de ley de enjuiciamiento de magistrados - presentados por Luis V. Varela y por una comisión especial integrada por Santiago M. Bengolea, Roque Sáenz Peña y José Manuel Estrada- entregados a los diputados con anticipación. Previo al debate, se pidió a la Cámara que, por votación, determinara el proyecto que serviría de base para la discusión en general. Tras duras discusiones, se optó por el de la comisión. ${ }^{59}$

Por falta de quórum, se levantó la sesión y, al día siguiente, el presidente invitó a los diputados a hacer uso de la palabra "sobre los proyectos en discusión con la libertad en el debate que el reglamento les acuerda en este caso". ${ }^{60}$ Esto no sucedió porque Bengolea y Varela generaron una discusión en torno a la posibilidad que presentó el primero, de crear una comisión que confrontara ambos proyectos. Varela se oponía a esta opción porque consideraba indispensable la participación de todos los diputados para legislar una resolución constitucional.

La respuesta de Vicente Fidel López define lo que se estaba discutiendo, se trataba de "un pequeño Código relativo al juzgamiento de magistrados", para lo cual debía darse "un voto de confianza a los estudios hechos por las personas peritas, encargadas de formularlos, porque es imposible que los señores diputados puedan improvisar en un momento un juicio propio y completamente adaptable a la cuestión que se debate". ${ }^{11}$ Se optó por elegir un proyecto y comenzar la discusión de un "asunto tan grave, tan serio y de tanta trascendencia".

A instancias de José María Moreno, se votó y se aprobó en general el proyecto de Varela, pues el mismo Bengolea había dicho que era más completo que el suyo. Los debates se extendieron durante seis sesiones. Por este motivo, hemos intentado centrarnos en los temas más espinosos que surgieron durante la discusión, en particular de los artículos. Prestamos especial atención a la elección de los miembros del jury, la condición de profesor en derecho para integrarlo, la jurisdicción del jury y la definición de actos de mala conducta.

\footnotetext{
${ }^{59}$ La comisión especial fue conformada a partir de una denuncia formulada ante la Cámara de Diputados por dos magistrados del Departamento del Norte. Por encargo de sus compañeros, Bengolea redactó el proyecto y se los pasó para que hicieran las observaciones correspondientes. Estrada manifestó su disidencia y Sáenz Peña aceptó el proyecto en general. Estando la comisión en mayoria, se presentó el proyecto y Varela lo creyó deficiente, por lo cual hizo una exhaustiva revisión de la que surgió su proyecto. Cámara de Diputados, sesión del 23 de octubre de 1877, Presidencia del Doctor Sáenz Peña, p. 1067.

${ }^{60}$ Cámara de Diputados, sesión del 24 de octubre de 1877, pp. 1082-1098.

${ }^{61}$ Cámara de Diputados, sesión del 24 de octubre de 1877, pp. 1090.
} 
En cuanto a la elección de los miembros del jury, el debate se generó entre quienes sostenían la elección del jurado realizada por la Cámara, y quienes defendían el sorteo entre los conjueces de la Suprema Corte o los abogados de la matrícula. En el primer caso, el riesgo era la parcialidad, mientras la segunda posibilidad podía eliminar la responsabilidad de la elección nominal. Finalmente, ganó la conformación del jurado por sorteo, con suplentes para reemplazar a los jueces recusados. ${ }^{62}$

Fue más complejo definir qué se entendía por profesor de derecho; para Varela, en el lenguaje de la comisión, era sinónimo de letrado. Para López, profesor era, en el lenguaje vulgar, el que enseña, pero, en el lenguaje jurídico, el que estaba patentado como tal. Según el uso en la Constitución, era el que profesaba la ciencia del derecho, aquel que hacía de su estudio la profesión de su vida, no el que la enseñaba y que tal vez no hacía del estudio del derecho su profesión. Pero Varela insistió en que se refería a los abogados profesores de derecho, para formar un tribunal científico, porque el "juicio que emita el tribunal tiene que ser esencialmente científico”, por abogados cuyos conocimientos no pueden existir sino en quien fuera al mismo tiempo profesor de derecho. ${ }^{63}$

Entonces, la tensión se intensificó entre quienes leían en la Constitución las diferencias entre abogado, como letrado que podía abogar o ser jueces, y quienes definían al doctor en derecho como quien sabía ad docere, enseñar. Las posturas enfrentadas superaban absolutamente la definición del perfil de los miembros del jurado y contenían en sí una problemática que se debatía en otros ámbitos, relacionada con la formación del abogado, la práctica de la profesión y la magistratura. Quedaba tanto por recorrer en estas cuestiones que se trasladó al texto de la ley el término constitucional profesores en derecho sin ninguna aclaración.

El siguiente punto ríspido fue la definición de la jurisdicción del jury. La Constitución creó este tribunal para juzgar a los magistrados con la facultad de declarar la culpabilidad o inculpabilidad del acusado. Luego, debían remitirse los antecedentes al juez ordinario, para que aplicase las penas correspondientes, por lo cual el jurado no podía tener jurisdicción penal. ${ }^{64}$ Sin embargo, Varela insistía en que el jurado no sólo tenía una jurisdicción política, sino también criminal, al preparar la acción penal -como era funcionario penal el juez de instrucción en materia criminal- sin dictar sentencia.

\footnotetext{
${ }^{62}$ Cámara de Diputados, sesión del 24 de octubre de 1877, pp. 1094-1095.

${ }^{63}$ Cámara de Diputados, sesión del 25 de octubre de 1877, pp. 1100-1101.

${ }^{64}$ Cámara de Diputados, segunda sesión extraordinaria del 9 de noviembre de 1877, p. 1204.
} 
También se imponía pena, consistente en la multa aplicada al acusador temerario y calumniador. Era una verdadera jurisdicción penal la que ejercía el jury. Esta postura no tuvo recepción en la Cámara y quedó establecida la jurisdicción del jury limitada a suspender en el ejercicio de su cargo al juez acusado y a declararlo culpable o no culpable del hecho que se le imputaba. Finalmente, quedaba por definir qué se entendía por mala conducta, contraria a la buena conducta que aseguraba al juez la permanencia en su cargo. Entra aquí en debate una cuestión primordial sobre la conducta privada del funcionario público.

Para Varela, la mala conducta privada, fuera del oficio de juez constituido, implicaba "primero, la ebriedad habitual; segundo, el vicio del juego por dinero [...] tercero, la frecuentación y trato de lugares y gente de mala reputación conocida; cuarto, cualquier otro acto que produzca escándalo incompatible; quinto todo acto de indignidad o indecoroso no punible como delito o culpa, pero que constituye indignidad para el carácter que desempeña el juez". ${ }^{65}$

La sociedad no podía admitir los fallos de estos jueces y debía denunciarlo ante el jurado, para que lo destituyera sin pena. Pero, para Aditardo Heredia, el artículo constitucional hablaba de las faltas o delitos cometidos por los jueces en el desempeño de sus funciones. La destitución era un castigo excesivo para un desorden de la vida privada y la pena la debía establecer el juez del crimen. Luis Sarmiento intentó encontrar un punto de equilibrio, sosteniendo que la separación o destitución de un juez del ejercicio de sus funciones por actos de mala conducta importaban "un acto destinado a preservar a la administración de justicia del contagio que puede producir en ella los malos elementos".

No se trataba de un castigo por ser borracho, jugador o vicioso, sino que era necesario separar de la administración de justicia los elementos de esta naturaleza. No había delito y no había pena que aplicar, era "un medio salvador y necesario para preservar a la administración de justicia de la corrupción". En el otro extremo, Aditardo Heredia propuso eliminar "mala conducta" del artículo para no "mezclarse en la vida privada de los magistrados". ${ }^{66}$

La cuestión se terminó de definir en la revisión realizada en la Cámara de Senadores, donde se establecieron como "actos de mala conducta denunciables ante el jury, todos aquellos que por su reiteración se hubiesen hecho notorios y a juicio del jury fueran depresivos de la dignidad de un magistrado". También quedó delineada la incapacidad denunciable como "enfermedad física o mental que impidiese a los jueces el desempeño regular de sus funciones,

\footnotetext{
${ }^{65}$ Cámara de Diputados, tercera sesión extraordinaria del 14 de noviembre de 1877, p. 1217.

${ }^{66}$ Cámara de Diputados, tercera sesión extraordinaria del 14 de noviembre de 1877, p. 1219.
} 
y la ignorancia de las leyes o procedimientos judiciales, reveladas al jury por actos sucesivos del mismo funcionario". ${ }^{67}$ Tanto la mala conducta como la incapacidad quedaban defınidas por la reiteración.

\section{Conclusiones}

La necesidad de contar con un medio de control de la función jurisdiccional del magistrado estuvo presente como atribución del Gobierno judicial, desde el antiguo régimen. Hemos intentado descubrir los cambios que se generaron desde el juzgamiento entre pares hasta el juzgamiento por un jurado determinado al efecto. Esta transición estuvo marcada por el artículo de la Constitución provincial, el cual permitía hacer uso de los viejos mecanismos hasta que los nuevos estuvieran implementados. Ello no implica un devenir lineal, pues hemos podido observar que cada paso estuvo signado por debates, marchas y contramarchas.

En este contexto, podemos destacar tres cuestiones que surgen del proceso judicial y de los debates legislativos. En primer lugar, es fundamental percibir el papel de la opinión pública y de la prensa en los reclamos de una sociedad que conocía sus derechos y el procedimiento para defenderlos, como también dimensionar los alcances que tenía en el siglo xix. Como indicamos en la introducción, es cierto que se trataba de una parte de la sociedad. Sin embargo, ello no invalida la aspiración, al menos teórica, de fundar las bases de un sistema donde "cualquiera del pueblo" pudiera, por delitos o faltas cometidas en el desempeño de sus funciones, acusar a un juez ante un jury calificado.

En segundo lugar, hemos podido vislumbrar los recursos que ofrecía el sistema para preservar "espacios grises", como los que se utilizaron para dejar sin efecto la primera denuncia contra Agrelo o para alimentar la confianza de sus cómplices en que él podría salvarlos de la cárcel, eludiendo el proceso judicial. En tercer lugar, es sugerente el debate sobre la delimitación de lo público y lo privado en el ejercicio de la función judicial, que puede trasladarse a otros

118 ámbitos de la administración. Este es un problema que aún no se resuelve y que podemos observar a diario, ¿cuál es el límite de la buena conducta de un funcionario?, ¿cuáles son los medios para juzgarlo y determinar los alcances de su conducta?

Hasta aquí, podemos asegurar que, llegado el momento de establecer la duración del magistrado en el ejercicio de sus funciones, se enfrentaron las garantías del ciudadano con las garantías para el juez en el ejercicio de su

${ }^{67}$ Cámara de Senadores, sesión 19 del 18 de julio de 1878, pp. 355-365. 
función. La movilidad o la inamovilidad estaban determinadas por un poder judicial que debía velar por los intereses y las libertades particulares. Asimismo, éste debía contener los abusos de los poderes políticos, pero también debía garantizar a todos la independencia del juez, por la duración de su empleo mientras respondiera a la confianza depositada en él.

Esto podía asegurarse a través de elecciones periódicas o de la permanencia en su cargo mientras durara su buena conducta. Pero, en el primer caso, los jueces quedarian en manos de las fracciones políticas y, en el segundo, no tendrían estímulo para estar a la altura de la ciencia, conocer sus ideas dominantes y sus progresos. Finalmente, se optó por la inamovilidad de los jueces con un sistema de enjuiciamiento legislado.

En función de nuestra preocupación por aportar, desde la historia, herramientas para una mejor administración de justicia, es importante recordar que el régimen de enjuiciamiento de magistrados no interfiere con las facultades conferidas a la Suprema Corte de Justicia de la provincia de Buenos Aires, por el artículo 164 de la Constitución Provincial y artículo 32 de la Ley 5827, de la Ley Orgánica del Poder Judicial, en cuanto determinan el ejercicio de la superintendencia y Gobierno judicial. El ejercicio de la potestad disciplinaria por parte de los órganos del Poder Judicial tiene como función asegurar el prestigio, la eficacia $\mathrm{y}$ el funcionamiento institucional de esta rama de gobierno. ${ }^{68}$ 


\section{Bibliografía}

"Acuerdos y sentencias dictadas por la Suprema Corte de Justicia de la Provincia de Buenos Aires, Autos acordados desde 1810, acuerdos extraordinarios, resoluciones y noticias referentes a la administración de justicia”, Segunda edición autorizada, realizada por el secretario de la Suprema Corte, Aurelio Prado y Rojas, Buenos Aires, Jacobo Peuser, 1892.

Alonso, Paula, Construcciones impresas. Panfletos, diarios y revistas en la formación de los Estados Nacionales en América Latina, 1820-1920, Buenos Aires, FCE, 2004. Bonaudo, Marta y Sonzogni, Élida, "Los grupos dominantes entre la legitimidad y el control”, en Marta Bonaudo (dir.), Nueva Historia Argentina. Liberalismo, estado y orden Burgués (1852-1880), tomo 4, Buenos Aires, Editorial Sudamericana, 1999. Brianti, Susana Alicia, "El jurado de enjuiciamiento de magistrados y funcionarios de la Provincia de Buenos Aires y la Suprema Corte de Justicia. Facultades", Buenos Aires, La Ley, 2008.

Corva, María Angélica, Constituir el gobierno, afianzar la justicia El Poder Judicial de la provincia de Buenos Aires (1853-1881), Rosario, Prohistoria ediciones-Instituto de Investigaciones de Historia del Derecho, 2014.

Corva, María Angélica, "La Administración de Justicia, una mirada desde la Historia del Derecho, Portal Jurídico Interdisciplinario Pólemos. Disponible en: http:// polemos.pe/la-administracion-justicia-una-mirada-desde-la-historia-del-derecho/

CoRva, María AngéLICA, "El primer ensayo de organización judicial para el estado provincial de Buenos Aires (1821-1825)”, Justicias situadas. Instituciones, agentes, culturas y espacios (entre el Virreinato Rioplatense y la República Argentina, 1776-1864), La Plata, FAHCE-UNLP, EN PRENSA.

De la Colina, Salvador, Derecho y legislación procesal. Materia civil y comercial, tomo 1, Buenos Aires, Librería Nacional J. Lajouane \&t Cía. Editores, 1915.

De LÁzzARi, Eduardo Néstor, “Apartamiento preventivo en el régimen de enjuiciamiento de magistrados de la Provincia de Buenos Aires”, La Ley, año 78, núm. 41.

Garriga, Carlos, "Sobre el gobierno de la justicia en Indias (siglo XVI-XVII)", Revista de Historia del Derecho, núm. 34.

Goldman, Noemí, "Crisis imperial, Revolución y guerra (1806-1820)", en Noemí Goldman, Nueva Historia Argentina, Revolución, República, Confederación (1806-1852), Buenos Aires, Editorial Sudamericana, 2005.

LetTieri, Alberto, La construcción de la República de la opinión, Buenos Aires frente al interior en la década de 1850, Buenos Aires, Prometeo Libros, 2006.

Malaver, Antonio, Curso de procedimientos judiciales en materia civil y mercantil, Buenos Aires, Imprenta de Pablo E. Coni, 1875.

Molina, Eugenia, El poder de la opinión pública. Trayectos y avatares de una nueva cultura politica en el Río de la Plata, 1800-1852, Santa Fe, Universidad Nacional del Litoral, 2009. 
MYERS, JoRge, Orden y virtud. El discurso republicano en el régimen rosista, Argentina, Universidad Nacional de Quilmes, 1995.

Palacio, Juan Manuel y Candioti, Magdalena, Justicia, politica y derechos en América Latina, Buenos Aires, Prometeo Libros, 2007.

Paolini, Jorge OMAR, El enjuiciamiento de magistrados y funcionarios, Buenos Aires, La Ley, 1992.

Parry, Adolfo, Responsabilidad de los Magistrados de la provincia de Buenos Aires, La Plata, Taller de Impresiones Oficiales, 1923.

Pasquali, Patricia, “El periodismo (1852-1914)”, Nueva Historia de la Nación Argentina, La configuración de la República independiente, 1810-1914, tomo 6, Buenos Aires, Academia Nacional de la Historia - Planeta, 2000-2001.

Ravignani, Emilio, Asambleas constituyentes argentinas seguidas en los textos constitucionales, legislativos y pactos interprovinciales que organizaron politicamente la Nación, tomo 6, Buenos Aires, Talleres Jacobo Peuser, 1939.

SÁbato, HiLdA, Ciudadanía política y formación de las naciones. Perspectivas históricas de América Latina, México, Fondo de Cultura Económica, 1999.

SÁbato, Hilda, Buenos Aires en armas. La revolución de 1880, Buenos Aires, Siglo XXI, 2008.

SÁBATo, HiLdA, "Los desafíos de la república. Notas sobre la política en la Argentina pos Caseros”, Estudios Sociales, revista universitaria semestral, año 24, núm. 46.

Santa Cruz, José María, El Poder disciplinario judicial. Responsabilidad administrativa de magistrados, funcionarios y empleados, La Plata, 1978.

Ternavasio, Marcela, "Construir poder y dividir poderes. Buenos Aires durante la 'feliz experiencia' rivadaviana", Boletín del Instituto de Historia Argentina y Americana "Dr. Emilio Ravignani”, núm. 26, segundo semestre, 2004.

Varela, Luis, Plan de Reformas de la Constitución de Buenos Aires, La Plata, Talleres de impresiones oficiales, 1907.

ZorRaquín Becú, Ricardo, La organización judicial argentina en el periodo hispano, Buenos Aires, Librería del Plata, 1952. 